\title{
Learning Along with Your Students: Projects from the Graduate Diploma of Computer Education
}

\author{
John S. Murnane \\ Melbourne Graduate School of Education, The University of Melbourne \\ jmurnane@unimelb.edu.au
}

\begin{abstract}
This Chapter deals with the early development of Computer Education for teachers in Victoria, Australia, through a set of Research and Development (R\&D) Projects that formed a large part of a Graduate Diploma in Computer Education (GDCE) at Melbourne State College, later part of The University of Melbourne. The early years of the GDCE, coincident as they were with the advent of the microprocessor and the desktop computer, reflected and indeed influenced the development of Computer Education in Victorian schools. The Projects provide an informative insight into the teachers Professional Development in Information Technology, the state of educational computing, and the uses to which computers were being put in Victorian schools in the 1980s and early 90 s.
\end{abstract}

Keywords: Computer Education, Professional Development, early computing in Victorian schools, educational impact of the microprocessor.

\section{Introduction}

When the GDCE began in 1980 the computing tools school teachers had to work with were absolutely minimal, although many of the coming developments in IT were already clear to see, if not already in existence. The projects therefore tell a story of teachers not only struggling with the educational psychology and philosophy of using a computer in a classroom, with its consequent impact on the way they taught and their students learned, but frequently having to write the software or even build the hardware themselves. As the decade progressed and the tools because available, the projects turned to more educational and sociological matters as the teachers pioneered the IT revolution with their students.

The Research and Development Projects, being by design heavily practicallyoriented, provide an informative insight into the teachers Professional Development in Information Technology and the use to which computers were being put in Victorian schools in the 1980s and early 90s.

\section{Early Days}

Teacher education about computers began at Melbourne Primary Teachers' College (later Melbourne State College via a series of mergers) in $1970^{1}$. The first students

\footnotetext{
1 'Primary' Teachers Colleges prepared teachers for Elementary schools covering Preparatory to Year 6, with an age-range generally from 5 to 12 .
} 
were entering the final year of the then new Diploma of Teaching (Primary) and J. G. Angus, Head of Mathematics, was looking for someone 'to do something with computers' with Third Year students taking Mathematics as an option. I happened to be enrolled in the Computer Science course at the Royal Melbourne Institute of Technology (RMIT) and, having some tertiary Mathematics as part of that, was hired by Angus to teach Mathematics Method at First Year and 'Computers' to his group of Third Year Mathematics students. (The Dip. T. (P) prepared teachers for Elementary schools and allowed trainees to specialize in a limited number of Second and Third Year options.)

Even thinking about the role computers might play in a Primary classroom was very long-sighted for 1970. In an interview in 2003, Angus recalled some of the factors:

- Looking to the future: to have some Primary teachers who could have some input into 'what computing finally arrived at past calculating machines.'

- Transition: moving to more equality between Primary and Secondary teachers. [At the time Primary teachers were generally regarded as secondclass in academic background.]

- To somehow attract College Staff who knew something about computers.

- To be prepared for the future by providing a sprinkling of teachers in Primary schools who knew about computers, rather than just having these teachers in Secondary Schools.

(J. G. Angus: telephone interview with J. Murnane, 16/9/03).

In the five years that followed, RMIT allowed the Third Year Mathematics classes to use its Elliot 803 computer for two hours once a week. The 803, a Second Generation machine, was used to run Algol 60 programs, not an activity particularly relevant to a Primary classroom but one which was in-line with Angus's desire to begin to sensitize and interest some Primary teachers in the possibilities they promised. (It was also about the only thing the computer could do apart from running Machine-code.) I have fond memories of standing in a classroom, most of the walls of which were taken up by the computer, with twelve rather bemused student teachers, telling them that 'One day, when you have one of these in your classroom, you won't be doing what we've just been doing, but it will be exciting and powerful, and it will change the way your students learn and the way you teach'. The students were clearly very skeptical, but the Intel 4004 'computer on a chip' had arrived on the market in November 1971 (Mazor, 1995) and was clearly pointing the way to the PC, if not in form, at least in promise. The potential for getting away from just writing a program towards information processing and communication were already obvious. It just took a little time ${ }^{2}$.

\footnotetext{
${ }^{2}$ To put the birth of the educational computer in context, release dates for early Microcomputers used in Victorian schools were: Tandy TRS-80 Model 1: November 1977, Apple ][: June 1977. Apple ][ Plus: June 1979, Apple ][e: 1983. Commodore PET: 1977. VIC-20: 1981. Commodore 64: 1982. For larger machines see Tatnall and Davey (2004).
} 
Over the next five years the College progressively acquired its own computers and at the same time more lecturers with an interest in, if not actual experience with computers were recruited, some coming with a merger with the Melbourne Secondary Teachers' College.

\section{The Graduate Diploma in Computer Education}

In 1978 a proposal was submitted for a Graduate Diploma in Computer Education (GDCE) (Melbourne State College, 1979). This course, the first of its kind in Australia, was designed to introduce computers in all their (current!) aspects to practicing teachers at all levels. It took in its first 30 'students,' all qualified and practicing teachers, in 1980. Given its early origins in relation to the penetration of computers into Victorian schools, the GDCE was conceived as a means to develop ideas about ways for using computers in Education and to implement and research some of these in practice, as well as simply teaching about them and their educational potential.

The course was designed to be taken part-time over two years. Generalizing somewhat, Year 1 was an introduction to all the aspects of computing relevant to education that could reasonably be crammed in. In their Second year the teachers were to consider and experiment with their own ideas for using the technology in their classrooms. A large part of this was a Research and Development (R\&D) Project, conceived as a major way of progressing the use of computers in the classroom. (It is a rare moment in Education when a course involves the students in developing large sections of the discipline itself!) There was also considerable emphasis on documenting, analysing and reporting the results of trying out these new ideas: the lecturing staff, drawn from a wide variety of academic areas, were determined to explore and document ways that a student could really learn in conjunction with a computer.

To this end, fully half the Second Year of the course (one quarter of the total course points) was devoted to the R\&D Project. In line with the objective of helping to develop educational computer use, copies were retained and made available for study and research ${ }^{3}$ (Melbourne State College, 1987, p. 19). The subject ran in this form from 1981 to 1993 and the project Reports provide an interesting insight into what Victorian teachers were thinking about IT and Education, and what they were actually doing (or not doing) with it in their schools. In 1978, when the GDCE was being developed, the ' $\mathrm{C}$ ' in ICT was largely absent. The Course Proposal refers only to 'computer technology'. The first project to even mention Communication was from 1987 and the next, 1993.

Student records show that 254 students passed the subject between 1981 and 1993 and a Report from each should have been preserved. In actuality, 147 have survived the initial collection process and several major changes in storage location. This still

\footnotetext{
${ }^{3}$ While each project was double-examined by the supervisor and another (internal) staff member, they do not have the standing of an externally-examined thesis and were not subject to external editing and peer review. Hence they are not included in the Reference list. Where a direct reference has been made to a particular Report, the name of the author, title of the project and date are given inline in the text.
} 
represents a considerable collection of material, roughly a stack of single-sided A4 paper 2 meters high. Three years are particularly bad. Only one from each of 1984, '89 and ' 91 survive. A total of 39 from those three years are missing. Nevertheless, within the limitations detailed below, the surviving material gives an interesting and vibrant picture of the early development of Educational Computing in Victorian schools. They constitute a valuable background against which to study the use of ICT in education at the time.

\section{The GDCE Research and Development Project}

"The programming took up much of the time allocated to the Project."
(C-A. Cartledge, The Use of Computers in Year 9 Mathematics Work on
Fractions, 1983)

The Project had two aims:

- To enable the teacher to achieve first-hand experience in the application of computer technology to a particular educational task.

- To enable the teachers to participate in the design, implementation and evaluation of a computer-supported resource for use in a school. (Melbourne State College, 1979.)

Following some face-to-face sessions dealing with research (project development, researching the literature and collecting and analysing data), a project would be agreed between each student and a supervising staff member. Assessment was on the basis of presentations at the beginning and end of the subject and a 6,000 word report. As can be seen from the Aims, the emphasis was on researching something practical with a computer in an educational context. The projects are notable in the large number and wide range of backgrounds in the supervising staff, an indication of the wide interest in computers in Education at the time.

In general, while the students made obvious efforts to bring academic rigor to the analysis of their data, the earliest Projects often suffer from obvious shortcomings to be expected of the period:

- The almost total absence of computers in schools. Even having one computer in the school was a challenge for many and getting time away from the Computer Science or Mathematics teachers was difficult. (GDCE students were still reporting this as a problem into the late 90s.)

- There was very little suitable software. Historical data on when applications such as word processors, spreadsheets, games and financial packages became available might suggest that this should not have been the case, but the R\&D Projects make it very clear that in the early 1980s, if a teacher needed software they mostly had to write it themselves. To encourage experimentation, 'outside' help with programming was specifically allowed provided it was fully acknowledged.

- The biggest problem was lack of time. 
A year might seem adequate to conceptualise, plan, execute and analyse Graduate Diploma-level research, but it was not generally adequate in the case of the R\&D projects even though students were encouraged to select a topic area towards the end of their First Year. Early sessions were taken with lecturers in conducting research, then a project had to be finalised and approved. Most projects would then require the agreement of the appropriate authority: the Victorian Department of Education, Catholic Education or individual school if privately run. Approval time could be short if the teacher was a staff member in a school in control of its own administration, but for large systems this could take months. By the time the project was ready, particularly if there was programming or system development involved, there would be little time to experiment and analyse, and most early projects show signs of curtailed development. These problems notwithstanding, in the first two years eleven projects were well tested in a classroom, four of them extensively, but eleven classroom-based projects had no testing at all. It is mainly the time factor which often stunted the desire to produce solid and reliable evidence that computers could offer, and indeed demand, radical changes to education and it is not generally possible, at this remove, to assert that many do so. In the first three years, only one before-andafter study (A. Gilding Atom Alchemy, 1981) was performed.

In 1981 there was little if any place for computers in the organised curriculum. It is noticeable that many teachers who, for various reasons, were dependent on observing other teachers using computers or participating in their classes, reported problems in introducing them into existing subject-structures. This could have been seen as a barrier, but since this is one of the things the GDCE set out to change, it was regarded as an objective and something the lecturing staff and students were determined to break down and change.

Externally, the educational philosophy of computers was changing rapidly. In the 1984-6 triennium \$18 million was allocated to the Commonwealth Schools' Commission Computer Education Program, a Federal Government initiative (Tatnall and Leonard, 2010, p. 103). This program recognised the need for students to have an understanding of the new technology, planned for the use of computers across the curriculum and emphasised access to the program by "girls and other disadvantaged groups" (Commonwealth Schools' Commission, 1984). The Victorian State Computer Centre was established by the Victorian State Government around the same time, offering advice and courses on educational programs, and beginning the provision of administrative software.

At this time the spread of computer types in schools was quite wide. S. J. Missen (A Format for the Evaluation of School Administrative Software, 1982) in a survey posted to 162 Secondary schools with 76 returns gives a typical picture. The project gives the break-down for individual schools, but collectively found: Apple ][: 26, Micromation: 16, Spectrum: 12, Cromenco: 5, BBC: 5, PDP 11: 4, PDP 8: 1 and Northstar: 1. The maximum for any one school was seven. Five schools had none.

Seventy computers spread over 76 schools do not go far. Missen also provides a comprehensive report of peripheral equipment, software and computer use. Only one school had a hard disk. Not surprisingly, Secondary schools in the 80s had to expect a 
"very wide range of computer experience in their Year 7 intakes" (J. M. C. Disken, Year Seven Computer Education, 1985) ${ }^{4}$.

The R\&D Projects show the arrival of computers in Victorian schools in increasing numbers from 1981 on. At that time, Melbourne CAE possessed a Digital Equipment VAX with 20-terminals and a small Lab of six Apple ][ computers. Single VAX terminals were scattered around the Departments, as were a few more Apples and a Tandy TRS-80s. In the early 80s the Apple Lab was expanded to 20 and later 20 networked BBC 'Model B' added.

The remainder of this chapter is concerned with an analysis of the projects: how the teachers themselves learned about Computers and Education, what computers were used for and how they were regarded by the bulk of teachers, students and parents. There is also a pleasant story woven into many Reports telling of their author's journey into the domain of the researcher, an unfamiliar area to many teachers of the time.

Leaving aside surveys and interviews, the projects, particularly in the early years, describe what is likely to be the teachers' and students' first experience with computers, educational or otherwise. Hence, in assessing the reported results, a large Hawthorn effect must be allowed for as well as an even larger reflected 'Experimenter' effect on the teacher/researcher (See Gottfredson, 1996, Murnane, 2010b, Rosenthal, 1996). Nevertheless, when looking across all the Reports a convincing consensus can be found. Individually the results might be questionable, but collectively they spell a coherent and convincing story.

\section{The 'Do It Yourself' Era}

"I have found it is possible to mis-spell 'camel' in dozens of ways." (A. Biggs, Burke \& Wills, 1982)

"These new channels will offer the possibility of a 'wired' world and will revolutionise the way we communicate with one another." (A. Hersbach, 1983)

"Accordingly I bought 100 meters of Telecom cable, unrolled it up the corridor and connected to the office system." (D. Walker, How Useful is a Communication System at Marian College? 1993).

In the first few years of the GDCE, unless a project involved studying an existing system, it was usually necessary for the teacher to write their own program, set up their own data system or even build their own electronics. Of 34 Reports submitted in 1981-82, 21 involved some sort of technical computing, either programming or setting up a computerised system using an existing application such as an author language. Most of these reports contained long and detailed Appendices on the program or system, often with lengthy Users' Manuals. None of this left much time for testing. Most programs were written in some form of Basic or Pascal, but one, an exploration of the historical 'Burke and Wills' expedition used 'SuperPILOT,' an

\footnotetext{
${ }^{4}$ Secondary Schools cater for Years 7 to 12 , with students generally 11 to 18 years of age.
} 
Author Language for the Apple ][, and another 'EXAMINER,' a multiple-choice testing presentation program.

An analysis of the programs paints a quite encompassing picture of the future of educational computing, at least until the advent of the Web. The teachers were certainly aware of the possibilities and were determined to exploit them, even at the cost of having to write the programs themselves. The GDCE First Year did include a small introduction to programming (in VAX Basic), but all of the programs went far beyond the requirements of this subject in length, and often complexity.

Eight of the 34 used a Computer Assisted Instruction (Programmed Learning) structure. This is not surprising, given the emphasis on it in the 70s. Lecturers in the main First Year subject, Computer Education, used CAI to teach about computers and their educational potential. A common thread running through many of them was the realisation that it is very hard to cover all possible responses unless some type of evaluation of student's responses, as against a set comparison list, can be used (Bitzer, 1976). Interestingly, while the Computer Education CAI sessions were received quite well, when the teachers were required to write programmed lessons of their own as part of the subject assessment there was a general reluctance, essentially a feeling that that was not the way they wanted to teach.

Fourteen projects were intended to teach specific areas of various disciplines, with eight in the Mathematics/Physics areas, including a very impressive symbolic algebraic manipulation program (D. Podhorodecki, An Experimental Symbolic Algebra Programme, POLLEX, 1983, extra programming assistance duly acknowledged), and two to teach programming. There were three from the Humanities, including two very early social simulations, one exploring local social interactions in an Australian neighbourhood for three to fourteen students (M. Arnold, The Great big Scoreboard of Life: An Educational Opera, 1992), and the other International Relations (C. J. Allitt, International Relations, 1983).

Nine projects involved a simulation. The potential power of the computer to simulate a complex set of interacting factors under user control had been emphasised in previous GDCE subjects. Projects included teaching Gas Laws, atomic structure and the two social simulations above.

The ability of the computer to automate various administrative tasks was clearly recognised, with eight projects dealing directly with the area. Four of these involved writing a set of programs implementing some facet of school administration. Two were surveys of useful programs or packages and one was a feasibility study of computerising the Education Department's Audio-Visual resources. There is an interesting non-anticipated outcome here that demonstrates something that can be found in many of the projects from 1981 to 1993: unsuspected, positive educational outcomes were found only after the project was implemented in the classroom.

While the administrative packages were developed specifically to improve efficiency and cut down the time teachers had to spend on bookwork, in many cases, once the system was in place and working, improvements in educational standards and flexibility were discovered. A timetabling program allowed more subject choices to be made available in Year 11 and 12 than could be offered under the previous manual system. A program to automate the school swimming sports results allowed a 
progressive score for each House to be announced, and a program to aid the Careers Teacher provided students with "many careers that they had not previously considered because these careers related directly to information they had input personally" (R. McKenzie, Computer Assisted Career Guide for Students, 1981).

A 1987 survey of Principals, Computer Coordinators and 'the person considered to be responsible for computers,' sent to 100 Western Metropolitan Region State Primary Schools (with returns of 94, $91 \& 79$ percent respectively), gives a picture of the state of 'administrative' computing at the time (G. R. Pratt The Application of Computers into Schools' Administrative Procedures, 1987). The Schools Administrative Computing Unit (SACU) inside the State Computer Education Centre was in the process of implementing a computerised administration package for State Schools. The Accounting Package was in the process of progressive installation by "SACU Officers," with Student Records and Library to come. The survey showed many respondents in schools waiting for installation "showed a great deal of concern" about the Accounting Package and its implementation, which Pratt attributes largely to "a lack of information" about it. Apprehension as a result of lack of knowledge and experience was to be a constantly reoccurring theme right through to 1993 .

One very notable attempt was made in analysing the 'social data' contained in the school enrolment records. The base was a 1980 student enrolment survey. Originally intended for analysis by hand, it was realised that far more could be done by computerising. Students were recruited to translate the data to mark sense cards and these were processed by a small set of analytical programs written by Buckley. In turn this lead to a revised 1982 survey with a tighter set of questions more suitable for data-processing. This required a narrowing of the type of data that could be collected: there was a limit to which open-ended questions could be replicated by selection lists, and the extent to which questions dependent on previous answers could be dealt with was also limited. One can read in this project a clear picture of things to come in the enhanced variety of information that can be economically extracted and the way computerised processing influences the array of data which can be collected and in turn imposes limits on the conclusions that can be drawn.

An obvious problem often identified in technical projects was the likely effective life of the system, given the short life of the computer or operating system it was written for. This was well demonstrated by a very ambitious computer controlled music synthesizer built and programmed by G. J. Hubbard (Computer Controlled Music Synthesizer, 1982). (See Mueller, 1982.) Finding existing synthesizers were well outside the school budget, (the MIDI interface did not appear until 1983), Hubbard built and programmed his own using a recently released sound generator chip. Unfortunately his choice of the COMPUCOLOR II, chosen for the ease to which it could be interfaced, doomed the project as COMPUCOLOR went out of business before the Project's due date. The synthesizer, and its programming, was not transferrable to a different machine.

Two projects from 1982 concerned Computer Managed Instruction but only one project in future years dealt with the idea. Prophetically, two dealt with Computer Crime. 
A thrill of satisfaction when a program, particularly one which has proven difficult, finally works as specified will be familiar to almost any programmer. These projects, while the programming was often fairly primitive, show that teachers were well aware of the promise and potential of computers and were determined to explore and exploit them, even if it meant a considerable amount of (unfamiliar) programming. Not only that, they express palpable excitement and satisfaction when their programs were used by staff or students:

"[I had] no knowledge at the time of [writing the program], of the feelings of excitement and wonder that would follow in trialling and evaluating [it], in addition to the desire to experiment with it in a variety of ways, just to see the effects it had on the students learning. Watching students, who in some instances would have great difficulty in applying themselves to a Mathematical task, 'invent' Mathematics and feel a great sense of achievement in doing so without the threat of 'marks' being awarded, was extremely rewarding” ( $C$-A. Cartledge, The Use of Computers in Year 9 Mathematics Work on Fractions, $1983)^{5}$.

This is an expression of perhaps the highest aim of GDCE staff: to find evidence for the belief that working with computers in a classroom could and would change the way teachers were teaching and students were learning.

\section{Teachers' Attitudes in the Early '80s}

"Ignorance more than fear is the major factor in this group of people confessing to being scared of computers."

D. Little, Attitudes of Secondary Teachers to Computers and Their Use in Schools (1982)

As might be expected, the Reports provide a uniform picture of a high level of enthusiasm for computer use in schools by those enrolled in the course. They are clearly excited at the idea of advancing the use of computers in their schools: it absolutely shines through. This might be expected of anyone prepared to enroll in a part-time course requiring two evenings a week for two years, but it is also in the interest and attitudes of their fellow teachers that future trends are evident. Not surprisingly, many of the early projects were concerned with ways to introduce computers to schools: meaning ways to interest and in-service otherwise disinterested teachers.

From the first year of the course the aim of introducing computers to schools was something that occupied the GDCE teacher's attention. Many early projects included

\footnotetext{
${ }^{5}$ This project utilised technology developed by A. Gilding for Atom Alchemy (1981) with assistance from staff member C. Bigum which allowed the students and the computer screen to be videoed as a split screen, allowing the student's operations and conversation to be analysed (Bigum and Gilding, 1983).
} 
an early chapter headed "Why Use a Computer in a Classroom?" or "Why use a Simulation?" In 1981-2, eight projects considered needs for, and/or implementation of, teacher Professional Development (PD) in the area. This was partly from an obvious need for other teachers to learn to use the systems created as part of the projects, but also as a general means of overcoming fear of the machine. Four projects considered teacher's attitudes as their main topic. Here, a generally quite positive attitude from non-users comes through, although some of that was related to a prosaic feeling that as computers were part of society, they had better be part of education.

Some projects, without being specific, do hint at a small proportion of outright hostility to computers. Most teachers with no or little exposure to them, while generally at least open to suggestions for their use, were worried about their lack of experience and stressed need for in-service professional development. There is also strong support for the need for local 'experts': teachers at the school readily available for individual consultation and help. This need for PD was reflected in applications for the GDCE. In the first five or so years we regularly had some 200 applications for 30 or later 40, places. The first selection 'cut' was to discard any applicant with less than four years of teaching experience. By the early 90s the quota was 75 and we were receiving just enough applications to fill it. By 2000 applications were down to around 30 per year.

The positive effect PD could have, (perhaps also with a growing familiarity), is shown in a Project set up to provide it. S. Lyon (Computers for Beginners, 1995) ran a set of six Units taken by staff and students (Table 1). Lyon documents a progression from the Units being taught by the Computer Coordinator to staff taking over and team teaching. As staff worked through the Units, the computers were moved progressively from a Laboratory to the classrooms.

Table 1. Improvements in computer use as a result of PD

\begin{tabular}{|l|c|c|}
\hline $\begin{array}{l}\text { Teachers using computers integrated with classroom } \\
\text { activities }\end{array}$ & April & October \\
\hline $\begin{array}{l}\text { Classroom teachers able to ‘boot up' a computer and run a } \\
\text { program }\end{array}$ & 3 & 13 \\
\hline $\begin{array}{l}\text { Students capable of loading a program and following } \\
\text { prompts }\end{array}$ & 15 & 350 \\
\hline $\begin{array}{l}\text { Student using word-processing without teacher } \\
\text { supervision }\end{array}$ & 4 & 200 \\
\hline
\end{tabular}

Rather conversely, Lyon notes that by the end of the project "all children in the grades ... are now using Word Processing in an efficient manner, [but] only three teachers are now using the process to aid their own writing," This could be related to the Apple ]['s problem in displaying lower-case letters. This problem shows in many early projects.

Over the entire area is the requirement for suitable software. If many GDCEenrolled teachers were prepared to write their own, their fellow teachers were, not 
surprisingly, uninterested, and until it was available, no amount of PD was going to attract them to computers. Further, software had to be accompanied by easy to understand, comprehensive documentation, preferably supplemented by relevant teaching material to help them get started in the classroom. Where programs had been written and used by other staff, mostly administrative applications, there was also a heavy emphasis on good reliability and ease of use as important factors in staff acceptance.

These attitudes echoed those in the general community. A. M. Scollary (Willing and Able? A study of the attitudes towards and the emotions aroused in adults by computers, 1986) found adult attitudes correlated with computer experience but had no other correlations for age or gender. A 1993 Report by J. Cullen (Students and Teachers Attitudes to Computers) surveyed four Secondary and twelve Primary schools with a total of 890 students. She found most staff participants had positive attitudes, though gender differences were evident, with female Secondary teachers the least positive. Student attitudes peaked at Year 7.

S. Keown (The Role of the Computer Coordinator: Greythorn High School, 1986) managed to fill 30 A3 pages with 68 tasks under thirteen main headings, many involving 'Help' and 'PD' for other staff, she considered the responsibility of the school Computer Coordinator. It would be an interesting list to compare with a current version.

\section{$7 \quad$ Student Attitudes}

“... students did not want to pack up, and there is evidence of some students being annoyed because they did not have the opportunity to try out some programs that they had thought up."

(C-A. Cartledge, The Use of Computers in Year 9 Mathematics Work on Fractions, 1983)

As noted, development of many projects, particularly those involving programming, did not leave much time for classroom testing, but of those that did, student response was strong and enthusiastic.

S. M. Shehata (Computer Assisted Learning in Matrices, 1981) contains a 20question Likert Scale student questionnaire examining student response to a set of programmed lessons. Notable are very strong positive responses to "The program helps me learn quickly" and "I prefer the program to regular instruction." Interestingly, "I find myself just trying to get through the program rather than trying to learn" produced eleven "Strongly agree" with four "Disagree" or "Strongly Disagree." Other questions suggest many students felt that the program was distancing them from their teacher, but their confidence in the material they were learning was heightened by the instant feedback they were receiving. They were unanimous that they enjoyed "working at the terminal" and all agreed it was "not boring." 
Most of these students were having their first computer experience and the fascination of just using a computer must be factored into the survey results. Even given the limitations of these small un-refereed studies, it would be interesting to compare these results with current student attitudes. To what extent were the positive student feelings expressed in many early Reports related simply to the novelty and excitement of using a computer? A teacher reported that a program computerising ACER Diagnostic Mathematics Tests written by me in 1980 was extremely popular with his Primary students "even though it was a test." (See Wong and Tatnall, 2009 for the "novelty effect.")

An interesting project was carried out at Odyssey House, a drug-rehabilitation facility, and Keilor Heights Secondary College (G. Pratley, The Computer: A Motivational Aid for Teaching Mathematics to Disinterested Low Achievers, 1987). Unusually for these Research projects, Pratley was able to use Control Groups with groups of students taught a Unit of Mathematics with and without using computers. This project showed attitudes to both computers and Mathematics in the "computer group' showed improvement over the non-computer group. "Pride of ownership" developed. As with many studies, familiarity with the technology brought more approval. As well as being very statistical, the study contains a small mountain of related, direct observations, including the comment that the Turtle was "personalized": "What is he doing?" (Author's emphasis.)

\section{From Writing Programs to Wider Issues}

"A small number of teachers had had previous experience in word-processing or programming.” (L. Bignall, A Student Reporting System for Secondary Schools, 1985).

From 1984 the Reports show a steady progression from writing a program or setting up an information system to more general reports of what teachers and schools were doing with computers. From 1984/5 projects begin mentioning 'closed' database packages including First Fleet (Wills, A. and Downes, 1985), Bushrangers, (House, Undated) and Gold Dust Island, (O'Carroll, 2012). Leaving aside 1984, '89 and '90 where only one Report from each year survives, the numbers of Projects involving technical computing are given in Table 2.

By 1985 most projects were concerned with broader issues and give a wide picture of what teachers and students within Primary and Secondary were doing with them. However, there is an understanding that the educational use of computers and their implications would only become clear with universal school use: "By 1990 we might well expect students will be all too familiar with many of the social, vocational and leisure time implications of the technology" (J. M. C. Disken, Year Seven Computer Education, 1985).

Table 2. Projects involving technical computing by year

$\begin{array}{cccccccc}1983 & 1985 & 1986 & 1987 & 1988 & 1990 & 1992 & 1993 \\ 6 \text { of } 12 & 7 \text { of } 18 & 10 \text { of } 26 & 6 \text { of } 19 & 1 \text { of } 6 & 1 \text { of } 6 & 5 \text { of } 12 & 0 \text { of } 6\end{array}$


There was also a gradual but significant increase in emphasis on the way computers can allow students to manage their own learning. There are many references to computers helping students to study independently, take more responsibility and make their own discoveries. This is in contrast with current trends to sheet responsibility for student learning directly home to the teacher, making teaching, in the words of Ken Robinson, "teacher-proof" (Robinson, 2009).

From 1985 the projects show progressively more classroom (or whole-school in the case of administrative programs) testing, with decreasing necessity to write programs. The Reports also contain evidence of a growing level of GDCE staff input and guidance. By 1987, First Year students were being provided with an 80-page 'Handbook,' much of which was intended as preliminary reading and help for the R\&D Project. Twelve pages of the companion 41-page 'So You're Teaching in the Grad Dip Comp Ed' provided guidance for R\&D Project staff.

\section{Computers at Preschool and Preparatory Grade Level}

There was a continuing interest in using computers at Kindergarten and Preparatory (Prep) levels with several using the same games (Kids at Work, Sticky-Bear Shapes, Juggles Rainbow and Face-Maker were particularly popular) and also 'One-Key' Logo and a Turtle. The Reports show children's interest observed to vary widely with a preference for working in a small group: "[I]t was rare to see single child at the machine" (K. N. Kean, Computers in the Preschool; An investigative case study, 1986).

Computing in Early Childhood Education (B. M. Todd, 1986) contains an investigation at one preschool with 24 children and a Commodore 64. To find out how intuitive the children found the computer a minimum amount of instruction was given in its use. The children were reported as finding no particular problems in its operation and to be choosing the computer as "play equipment". They preferred to participate 'hands-on' rather than watch and averaged nine minutes per turn. This type of experiment would no longer be very practical because most children will enter Preschool with experience at using a GUI. Todd Included a comprehensive Literature Review that showed most relevant publications from the USA concentrated on teaching about the computer, while those from Australia largely concerned learning with a computer and stressed play.

Two teachers used the then-new "Tasman Turtle" 6 with One-Key Logo. H. Boyle (Introducing Computers to a Kindergarten, 1986) found it prompted interesting children's comments such as "Is the Turtle alive?" and reported a measure of parent interest. L. Jackson (Young Children and Computers, 1986) used a Tasman Turtle with 34 Preschool and Preparatory Grade children. Rather unusually for one of these projects, Jackson was able to include Pre and Post interviews to determine if there were changes in the children's understanding of what a computer was, and what it could do. Answers to 'What is a computer?' varied from "A thing that tells you things

\footnotetext{
${ }^{6}$ See later chapter by McDougall, Murnane and Wills.
} 
- how to make things - how to play things" to "It's a television with buttons." A question on 'what is a Robot' was often associated with the popular Transformers toys. Answers to these questions, while not without their own difficulty in interpretation, could be usefully compared against contemporary children.

\section{Programming and Robotics}

"The evolving program serves to remember all of his discoveries, and continually to accumulate and synthesize them." (Dwyer, 1971).

"I still had some students within the Computer Awareness course who expressed a strong interest in programming." (G. P. Bertuna TUTEPAK: Tutorial programming package, 1982).

"Both boys and girls asked to use the computer with LogoWriter in their free time." (J. A. Jones, Parent Participation, Gender Equity and Computers: One form of action, 1993.)

A considerable proportion of the literature from the 70 s and $80 \mathrm{~s}$ deals with the perceived advantages of teaching programming. (See for instance Abelson, Barnberger, Goldstein and Papert, 1976, Dwyer, 1970, Juliff, 1982, Kurtz, 1968, Papert, 1971, Papert, 1980). Some, such as Kurtz and Dwyer document specific examples, others rely largely on Educational connections to the languages themselves, such as the need to identify structures within tasks and document their temporal execution, split tasks into procedures and allot descriptive names to these and the variables. Robotics not only involves programing but construction, in which many of the same concepts apply. Inevitably the two areas go together.

A programming language, being a precise vehicle for communication, was thought to offer a way for students to document thought processes and instructions in clear and unambiguous ways (Papert, 1980, p 32). The program, when executed, would provide feedback on the validity of the instructions. A malfunctioning program was not a target for a poor mark, it was an aid and invitation to trace the cause and rectify it (Murnane, 2010a, Papert, 1980, pps. 22, 101).

A small but continuing interest in projects involving students learning to write their own programs continued to 1992. Seven projects dealt with it, ten if One-Key Logo is included as 'programming.' The 1983 Victorian Year 12 Computer Science syllabus (see below) listed four approved programming languages: A structured version of Basic, Pascal, Comal and MIT Logo (Victorian Department of Education, 1983). As these examinations are used for University entrance they are an important standard. No project dealt with Comal although one school was reported as using it (below). One project reviewed the literature on PROLOG (I. M. Renwick, Adventures in PROLOG, 1987).

There are no particular patterns through the Reports dealing with students writing programs, other than universally reporting an enthusiasm for the activity. 
S. Johnson (A case study in Mathematical ability, 1992) describes using LogoWriter with eight Year 8 volunteer Secondary School students. Test results in Mathematics are analysed as well as attitudes in the LogoWriter class. Weaker students showed the most Mathematical gains with improvement as high as $17 \%$. The Report is documented with a large number of student programs. Not all Logo experiments were successful. One was declared a failure because "there was little interest [from the teachers] in the topic" (S. Lyon, Computers for Beginners, 1985).

Software Projects for Level 11 Computer Studies/Science Students (M. Nugent, 1986) explored the educational philosophy for teaching programming through projects rather than a 'teach the language first' approach. Once again, it would be interesting to compare the associated questionnaire with current attitudes since the Report contains good reporting and evaluation. Findings on the use of Logo and a Robotic Turtle are especially interesting. TUTEPAK, Tutorial Programming Package Beginners Applesoft Basic (G. P. Bertuna, 1982) was a CAI introduction to structured programming in Basic, and Data Structures Took Kit (J. S. Schwartz. 1985), was written for Year 11 Computer Science. The development of a short course called An Introduction to Structured Programming in Pascal (J. Clark, 1982) was designed as one of a set of programming units for $\mathrm{TAFE}^{7}$. Concise and directly to the point, it could serve as a model for contemporary manuals in structured programming.

S. J. Snipe (Robotics in the Primary School, 1986) used Fisher Technic, a FloorTurtle and Lego. At the time the school had "no computers available for curriculum use" although it was developing a Computer Policy in the expectation of acquiring some. Snipe used his own Microbee computer, building and programming an interface to run Logo-programmed models. Here was another example of a teacher's work overtaken by wider events: although educational aspects met his expectations, part-way through the project Lego released its first Robotics kit containing all the elements he had been working on, albeit at a much higher cost!

F. A. Flynn used an Action Research/Participant Observation framework with eight Year 5/6 and eight Year 11 students working with Lego-Logo for the first time (A Study of Factors Affecting the Introduction of Lego Logo to Primary and Secondary Students, 1990). Flynn used "directed instruction" with two groups at each year-level and "open-ended tasks" with the two others. Looking for differences on the basis of gender, academic background, attitudes to school, group size and method of instruction, Flynn found inconclusive evidence for all factors and concluded that differences in achievement were due to individual students. There were clear differences in the 'engineering' side: students with prior experience with Lego Technic "achieved more than those students who had not used it" though students with "no previous experience with LogoWriter seemed to be at no great disadvantage. ... The students picked up the programming skills with a minimum of fuss."

\footnotetext{
${ }^{7}$ Technical and Further Education.
} 


\section{Year 11 and 12 Information Technology}

1981 saw the introduction into the Victorian Higher School Certificate (HSC) of a Computer Science course at Year 12 level. The syllabus followed what could be considered as a typical computing and information technology course at the time: programming, data structures, systems analysis and information systems. In 1987 the Year 11 and 12 certificates were replaced by a two-year Victorian Certificate of Education (VCE). With the change came Information Technology, a two-year sequence which has undergone considerable transformations over the years. (See Tatnall and Davey, 2010.)

Even though the GDCE was deliberately set up to cater for teachers requiring PD in teaching Senior IT courses, only two projects concerned them, one each from the HSC and the VCE. Findings were very similar.

A. B. Osborne (HSC Computer Science: A teacher's guide to some problem areas, 1985) reviewed the HSC Computer Science course. Although finding that teachers and students generally liked the syllabus, he found issues such as the course being too long, inappropriate topics and especially problems arising from students having an inadequate Year 11 IT background. Osborne used a set of interviews with Computer Science teachers together with a 14-school questionnaire. The languages in use were Basic: 6, Pascal: 7 and Comal: 1.

Reviewing the later VCE IT subject, A. Moylan (Teachers perceptions of VCE IT, 1992) found a similar liking of the syllabus but largely the same problem areas: parts as being "open ended" and "imprecise." Much more PD was required. Student keyboard and research skills were considered to be poor. Again the research was quite wide, with Moylan surveying 40 schools with a 50\% return rate, and includes responses from 100 Year 11 IT students. Most Year 11 students were planning to continue IT in Year 12. A broad range of teachers were teaching the subject with Humanities, Mathematics, Science, Computing and Commerce backgrounds. The project includes interesting data on computer ownership: $53 \%$ of students had a computer at home, $30 \%$ used it every day and $30 \% 3$ or 4 times a week. Most use was for typing assignments or games. (Note that this was prior to the WWW).

In 2014 enthusiasm for Information Technology as part of the curriculum has waned. Programming in particular has suffered, perhaps because of the range of applications which progressively become available decreasing its impact, but it still continues in some places. Enrolment in the VCE 'Systems' stream and its successor, IT Software Development, which contains the bulk of the 'technical' computing, has decreased markedly over the years. The statistics are not totally comparable, but as an indication, in 2001, 19,413 students passed the Year 11 IT Unit 1 and 13,356 passed Year 12 IT Unit 4. In 2012, 4,494 took Year 11 Information Technology, 2,944 took Year 12 IT Applications and 1,098 took Year 12 IT Software Development (Victorian Curriculum Assessment Authority, 2012). In my opinion, programming should be a small, but important, part of the curriculum. 


\section{English as a Second Language}

Only three comprehensive projects concerned English as a Second Language (ESL) but they tell an interesting story spanning eight years. The overall message is, once again, potentially good results put at risk by the lack of teacher preparation and PD: teachers with little exposure were skeptical at best. Since the Reports span the years 1985 to ' 92 , this continuing lack of teacher support is quite alarming.

Computers and English as a Second Language (M. J. Miller, 1985) contains a 'needs analysis' and a survey of 22 ESL teachers in eight schools as well as a description of a set of lessons with small groups with examples of student work. Programs used were The Bank Street Writer (found particularly effective), Logo, First Fleet, CriptoCube and Story Tree. Of the 22 teachers surveyed, only two had 'ESL inservice.' (Seventeen had no computer in-service at all.) Obtaining bookings for computer Labs was universally difficult with zero to 19 computers per school, typical numbers being nine to fifteen.

The preparatory sessions for the $R \& D$ Project put an emphasis on Action Research as a potentially useful methodology. Action Research is a cycle of planning, implementing and assessing a program. Because the experimenter is, of necessity, in control, it is very applicable to classroom experimentation (See Murnane, 2010a, Murnane, 2010b pp. 114-139). While many projects do show traces of this methodology, very few explicitly embed the experiment in it. One notable exception was Using computers With English as a Second Language Classes (A. White, 1986) which used a formal Action Research structure in a project providing in-service for seven ESL teachers at one school. White reported an initial "complete lack of confidence" in many of the staff, with the project only being kept alive by a few "committed and determined teachers." These commented on the "the effectiveness of the computers in stimulating oral language and social skills. These have been developed through the use of simulation games by all students" to Year 11 level. By the project's end, all but one were enthusiastic." The students were described as "enthusiastic and willing" though some commented computer sessions "could be boring."

D. Lazarevic (Computers and Their Use in English as a Second Language Learning Environment, 1992) obtained survey data from 200 students and 35 ESL teachers. A solid statistical data analysis again showed lack of appropriate software and teacher training. Over $50 \%$ of Secondary teachers gave negative answers to the question "Do you think computers useful for ESL." Attitudes to computers in ESL in schools were found to be generally poor but good in Language Centres. Some attitude and confidence differences related to gender were found with female ESL students reporting less use of computers than males.

\section{Word Processing and Process Writing}

An argument could be made that the Word Processor was the single most important software advance in educational computing, given its effect on written expression. 
Very few Projects before 1985 mention it and none deal with it other than in passing. This is possibly a reflection of the lack of software that would run on existing school computers, although this was changing rapidly. K. Daly (Word Processing and the Process Approach to Writing, 1985) lists 21 available Word Processors for the Apple ][, 12 for the PC, 6 for the BBC Model B and several available for other machines. At the time there were still thought to be negative aspects to Word Processors: Daly was still finding frequent references in the Literature to 'disadvantages' of Word Processors such as spelling and grammar checkers and a general fear that the Word processor would discourage students from proper essay planning.

'Process Writing' is a term applies to a cycle of development for written text. Sponsored be a variety of authors from the late ' $60 \mathrm{~s}$ it is a cycle of drafting, reviewing, and rewriting, often involving other students in the review stage. (See for instance Arms, 1983, Graves, 1983, Parker, 1972.) When it came to the rewriting stage, the Word Processor was an obvious enabler.

Daly provides a very large (for a 6,000 word project) survey of computing tools useful in teaching reading and expression including the first reference to 'Choose your own adventure' games in a Project. She covers keyboard skills and touch typing, finding that 'keyboarding' can profitably commence in Prep with touch-typing classes beginning in Year 4. (Three 1990 Reports deal directly with touch-typing. It seems that in 2014 it has all but disappeared from the curriculum, perhaps because it has been largely replaced with typing with the thumbs?) Daly discusses the educational use of the Word Processor and its use in Process Writing. Daly kept an anecdotal dairy of each lesson. She timed students in physical writing at start of the project and Word Processed writing at the end, finding "substantial" improvement. She noted major problems caused by not having the computers in her own classroom, something in common with most 'classroom' projects of the time. Each student filled out an 'attitude' sheet: "All stated that the computer made writing easier but had different preferences as to how they wished to incorporate it into their work," being roughly evenly split between writing the first draft by hand and those who would type from the beginning. A notable feature of the project is the insight it provides into Daly's own learning process as a teacher.

M. Said embarked on a rare project where he was able to compare two randomlyselected groups from a Prep classroom, one using a Word Processor and the other pencil and paper (Process Writing in the Prep Classroom using a Word Processor, 1986) The time element here was quite extensive for a project: twenty one-hour sessions. Despite the (acknowledged) difficulty of constructing a satisfactory regime to measure differences in oral and written language at this Year level, Said was confident that Word Processing had been shown to be effective for implementing Process Writing, something echoed by H. Gofron (Role of the Word Processor in the Process Writing Approach, 1993). "Both Year 4 class teachers ... have been overwhelmed with the enthusiasm the children have shown for wanting to use the computer for process writing." This, using a total of three machines, which "meant three or four children to one computer for twenty minutes at a time once a week." 
A very different approach to Word Processing was used by S. G. Graham (A Unit of Work Designed to Introduce a BBC Master 128 Computer to Grade 3/4 Through an Adventure Game Leading into Word Processing Manipulation, 1986). Graham used Adventure Games as an entry to Word Processing. He chose this as a way to promote "meaningful reading for a purpose, problem solving and group interaction specifically in the form of transactional speech and responding imaginatively in writing. ... Enthusiasm was overwhelming and a pleasant change." The study was very comprehensive, using Granny's Garden leading to writing using EDWORD 2. The project included an in-service for teaching staff and two parents who helped with the Word Processing lessons, all carried out using two computers. Graham used the results of a parent questionnaire, distributed before the experiment began and obtaining 66 responses, to involve parents in their children's work and invite their participation, required because the teacher could not provide the help required while students were working at the computers. Summaries of questionnaire responses are included in the Report.

\section{Gender and Social Issues}

"Gender equity studies have shown that there is a need to provide programs designed to support girls' education, particularly in computing." (J. A. Jones, Parent Participation, Gender Equity and Computers: One form of action, 1993.)

Differences in gender related to computers occur frequently in the literature of the time, but only occasionally in early projects, becoming a focus of interest from 1987. In general, Reports do not show great differences attributed to gender. J. Morris in a study of Primary students in Years Three and Six using LogoWriter (Gender: is it an issue in Primary computing classrooms? 1992) did find traces of a gender gap but considered that it "may be diminishing ... and may not be the issue that it once was." She concluded "the majority of children do not see computing as a male domain in the Primary school."

Similarly, M. Wilson (An Investigation of the Factors Involved in the Differential Attitudes and Responses of Boys and Girls in Computing. 40 Year 5 \& 6 Primary 1987) in a large statistical study using questionnaires before and after a computing unit, and computer-related tasks with observation of group dynamics, found no gender differences in attitudes towards computers or "their perceived stereotyping of them. ... Boys and girls displayed very favorable attitudes to computers and ... perceived the computer as a neutral object." There were significant differences in response to 'failure' situations: girls typically faulted their own lack of ability while boys faulted the system.

One area all Reports agree on is a tendency by boys to consider that they should have priority over girls for computer access. Morris found evidence to "support the theory that boys dominate girls in computer classes." J. A. Harris (Equity of Access and Participation in Computer Education Making a difference, 1993) observed that following a 'girls only' computer Unit, some girls became more assertive in 'claiming' use of the computer room. Echoing Morris, she found the boys objected to this, using what Harris describes as "guerrilla warfare" to reclaim the machines for themselves. 
D. Lazarevic (above), concluded, from a large survey, that female ESL students, compared to males, were less frequent computer users. S. Johnson (above) found an increase in confidence in female students during a Mathematics course using LogoWriter.

These relatively benign findings are contradicted in a 1993 study by J. A. Jones (Parent Participation, Gender Equity and Computers: One form of action). Jones used a multi-layered approach to assessing gender equity relating to computers, to investigate the effects of computer education on the attitudes and behaviours of female parents, and the effects on the attitudes and behaviours of her class: 21 Year 1 and 2 students. "Both boys and girls showed evidence of stereotyping. The girls were more likely to show stereotyped views, choosing one career for girls and one for boys. The boys however, were more likely to show stereotyped views when classifying work-both paid and unpaid. The boys were more likely to stereotype adult computer use. ... Most of the children believed that they would use computers in their adult life for either reading or writing." Jones found there was a "definite change in the children's perceptions of gender ... after their participation in [the] gender education program." Four parents took 'women only' classes. Jones found initial evidence of sex stereotyping in relation to work and play. There was also evidence of fear of computer technology. A multifaceted approach to gender issues and computer education for parents produced positive changes in attitudes and behaviour.

Two projects concerned children with Special Needs. G. E. Grigg (An Investigation of Software Available for Special Needs Students: Intellectually and/or Physically Handicapped, 1987) found from a survey that there was suitable software with many access devices available "which enable disabled students to interact with computers as effectively as their non-disabled peers."

M. Barcia specifically studied the Concept Keyboard and its effect on language development with 'special needs' students. He also conducted a parallel study in main-stream Prep and 5/6 grades. (An Investigation into the Concept Keyboard and its Effect on Special Education, 1987.) The case study confirmed positive results reported in the literature. A Logo Floor-Turtle was also used. The study also includes experiments with Special Needs students using various keyboard overlay, most of which were found to be inappropriate, though a 15-session study of one student did show progress. The overlays were useful in Prep but not as much in 5/6. The Report contains a very good evaluation of the stages Special Needs students were at or went through using a Floor Turtle. After some experience, and with no prompting, the students positioned themselves behind the Turtle before giving a command to move it (Papert, 1980 p. 63-4). On Methodology, Barcia notes the need to separate observation from being the teacher (See Murnane, 2010b).

\section{The Last Two Years}

"I hope this project will never finish." (D. Walker, How Useful is a Communication System at Marian College? 1993) 
The twenty projects from the last two years show a progressing maturity, not only in the teachers' confidence and maturity in using the technology, but in a steady decrease in 'technical' computing and an increase in social and general educational issues. There was still considerable interest in computer use in specific subjects (Legal Studies, Information Technology, ESL, Mathematics and Process Writing). The projects also increase in size, maturity and the quality of the research.

There was still considerable interest in Administrative computing with five dealing directly with it. Staff and student attitudes to computers were prominent, being the subject of five Projects. As with earlier Projects, they conclude that considerable Educational benefits can flow from automating administrative systems.

A 1987 project examined Electronic Bulletin Boards (T. P. Howard, Curriculum Dissemination via Electronic Bulletin Boards) but 1993 brought the first project to even mention eMail and electronic student communication (D. Walker, How Useful is a Communication System at Marian College? 1993). The Report contains an extensive survey of the communication programs available at the time together with some heartfelt comments on the frustratingly random difficulties encountered in using some of them:

Noise! Success, then 'No dialtone.' Such was the pattern for the next month. Sometimes we could log in and look at the AAP files. The next time the screen would fill with garbage. Sometimes the dreaded words 'No dialtone' would appear, and I would race to the front office to check they hadn't disconnected us or that a fax hadn't steamed up the data line, causing our puny signal to drop out. Year 11 continued with their database work, happy in continued success, whilst I wrestled with technology and yearned to return to my life as a Drama teacher.

Despite technical difficulties, Walker persevered, finally establishing a connection with a school in Vernon, Florida. This was the turning point of the project as the Year 11 s were at last "beginning to believe it might be real."

As the students began to write about themselves, Walker discovered many of the problems which are discussed in relation to the Web to this day:

I quickly discovered that there were two groups: The Incurably Honest and the Fantasy Freaks. The Incurably Honest wrote that life was drab in Australia, Deer Park was boring and school was a drag. The Fantasy Freaks wrote about their Capri sports cars and encounters with drug runners.

This contact showed up a difference between students in Victoria and the USA at the time in terms of sophistication and use of electronic communications. The letters from Florida turned out to be "fresh and friendly and very warm. ... Year 11 now have a splendid relationship with Vernon, Florida. ... Marian College now has two classes who can claim with quiet confidence that they exchange ideas, stories and jokes regularly with students in far-off Florida in less time than it takes to fly there." 


\section{Conclusion}

"The intrinsic fun of real computing should be preserved at all costs. It will translate into a joy for other learning if given half a chance." (Dwyer, 1971)

The 80s and early 90s were a great time for anyone involved in the use computers in the classroom. If the Reports paint one consistent picture it is of keen and enthusiastic teachers working around the shortcomings, batting down the difficulties and frustrations, reveling in the opportunities and learning along with their students, often to even better effect, convinced that what they are doing was not only exciting and vital but was indeed changing the way their schools and classrooms functioned. Computers were indeed changing way they were teaching and their students were learning.

\section{Postscript}

It is often said that in the relatively near future there will be no way to access the data on the current crop of computerised media such as CDs. Many of the early reports, mostly printed on dot matrix printers are already fading and are unreadable without the aid of a magnifying glass. The bindings are also coming apart. Some things do not change.

\section{References}

1. Arms, V.M.: The computer and the process of composition. Pipeline 8(1), 16-18 (1983)

2. Bigum, C., Gilding, A.: A video monitoring technique for investigating computer based learning programs. Melbourne Advanced College of Education, Carlton (1983)

3. Bitzer, D.L.: Plato, an adventure in learning. In: Seventh Australian Computer Conference. Advanced Press, Perth (1976)

4. Commonwealth Schools Commission. Report on Computer Education. Canberra, Australia (1984)

5. Dartmouth College. Demonstration and Experimentation in Computer Training and Use in Secondary Schools, Activities and Accomplishments of the first year. Hanover, N.H. (1968)

6. Dwyer, T.A.: Some principles for the human use of computers in education. International Journal of Man-Machine Studies 3(3), 219-239 (1971)

7. Gottfredson, G.D.: The Hawthorne misunderstanding (and how to get the Hawthorne Effect in Action Research). Journal of Research in Crime and Delinquency 33(1), 28-48 (1996)

8. Graves, D.H.: Writing: teachers and children at work. Heinemann, Exeter (1983)

9. House, A. (Undated) The bushrangers database (Online). National Library of Victoria, http: //trove.nla.gov .au/work/11737119?q\&sort=holdings+desc\&_ $=1380595819424 \&$ versionId=22448430 (accessed August 2013)

10. Juliff, P.: Programming — should we enjoy it or do it properly? In: Welch, R. (ed.) Ninth Australian Computer Conference, August 26-28, pp. 38-43. Mercury-Walch, Hobart (1982)

11. Massachusetts Institute of Technology. Logo progress report 1973-1975. Cambridge, Mass (1976) 
12. Mazor, S.: The history of the microcomputer-invention and evolution. Proceedings of the IEEE 83(12), 1600-1608 (1995)

13. Melbourne State College. Application for Accreditation of the Course for Graduate Diploma in Computer Education. Melbourne, Australia (1979)

14. Melbourne State College. So, you're teaching in the Grad Dip Comp Ed. Melbourne, Australia (1987)

15. Mueller, E.: New Product Review. FORUM International 2(2), 27-29 (1982)

16. Murnane, J.S.: Programming Languages for Beginners. Lambert Academic, Saarbrücken (2010a)

17. Murnane, J.S.: Researching in a Confined Environment. In: Benzie, D., Lai, K.-W., Reffay, C. (eds.) IFIP Working Conference: New Developments in ICT and Education, Université de Picardai Jules Verne, Amines, France, June 27-29. IFIP (2010b)

18. National Science Foundation, Washington, D.C. Teacher-Student Authored CAI Using the NEWBASIC/CATALYST System. Pittsburgh Univ., Pa (1970)

19. O’Carroll, R.: Gold Dust Island. Jacaranda Wiley (2012), http: / /www.gb64.com/game.php?id=11054\&d=33 (accessed October 2013)

20. Papert, S.: Teaching Children Thinking. Massachusetts Institute of Technology, Cambridge (1971)

21. Papert, S.: Mindstorms: children, computers, and powerful ideas. Basic Books, New York (1980)

22. Parker, R.P.: Focus in the teaching of writing: on process or product? English Journal 61(9), 1328-1333 (1972)

23. Robinson, K.: We need a creative revolution. Radio. Life Matters: Australian Broadcasting Commission (January 17, 2009)

24. Rosenthal, R.: Experimenter Effects in Behavioral Research. Appleton-Century-Crofts, New York (1996)

25. Tatnall, A., Davey, B.: The life and growth of Year 12 computing in Victoria: An ecological model. In: Tatnall, A. (ed.) HC 2010. IFIP AICT, vol. 325, pp. 124-133. Springer, Heidelberg (2010)

26. Tatnall, A., Davey, B.: Streams in the history of computer education in Australia. In: Impagliazzo, J., Lee, J.A.N. (eds.) History of Computing in Education, pp. 83-90. Kluwer, Boston (2004)

27. Tatnall, A., Leonard, R.: Purpose-built educational computers in the 1980s: the Australian experience. In: Tatnall, A. (ed.) HC 2010. IFIP AICT, vol. 325, pp. 101-111. Springer, Heidelberg (2010)

28. Victorian Curriculum Assessment Authority. Satisfactory Completion of VCE Units, Information Technology (2012),

http: //www.vcaa.vic.edu.au/Pages/vce/statistics/2012/section2/ vce_information_technology_12.pdf (accessed November, 2013)

29. Victorian Education Department. Victorian Higher School Syllabus. Australia, Melbourne (1983)

30. Wills, S., Bunnett, A., Downes, T.: Convicts and bushrangers: educational databases brought alive. In: Rasmussen, B. (ed.) The Information Edge: the Future for Educational Computing, Proceedings Australian Computers in Education Conference, Brisbane, pp. 117-126 (1985)

31. Wong, L., Tatnall, A.: The need to balance the blend: online versus face-to-face teaching in an introductory accounting subject. Issues in Informing Science and Information Technology 6, 319-322 (2009) 